\title{
Do Gender Moderate the Effect of Workplace Incivility on Job Related Outcomes?
}

\author{
${ }^{1}$ Khatiba Akhter ${ }^{2}$ Prof. Dr. Muhammad Aslam Asghar, ${ }^{3}$ Dr. Nazir Haider Shah \\ ${ }^{1} P h D$ (Education) Scholar, Mohi-Ud-Din Islamic University, Nerian Sharif, AJ\&K (Pakistan) \\ ${ }^{2,3}$ Department of Education, Mohi-Ud-Din Islamic University, Nerian Sharif, AJ\&K (Pakistan)
}

\begin{abstract}
This study was primarily intended to identify the moderating role of gender in the effect of workplace incivility on performance of teachers at job. The study initially established the direct effect of incivility on job performance and then probed the moderation of gender in the specified effect. Workplace incivility was identified in terms of rude, ignoring, and discourteous conduct of supervisors and colleagues at job place. The performance was examined by taking into consideration the specified job responsibilities and additional contributions made by the teachers voluntarily. For empirical analysis, the researchers selected a sample of 378 regular teachers from five public sector universities and responses on workplace issues were gathered through mailed questionnaire. Moreover, feedback regarding performance and contributions of teachers was sought from the respective departmental heads. Data collection instrument was adopted from some published studies and was comprised of widely used, tested, and reliable measures. For hypothesize direct effects, the analysis of collected responses was carried out with the help of structural equation modelling (SEM) in AMOS. The moderation of gender was probed by applying PROCESS macro in SPSS. Findings revealed a negative and significant effect of workplace incivility on each in-role and extra-role performance of teachers. Moderation of gender was only observed in the effect of workplace incivility on in-role performance. Similar moderation for extra-role performance component was not found. The study contributes to existing literature of workplace incivility by examining the moderating mechanism of gender and it offers different policy implications on the basis of findings.
\end{abstract}

Keywords: colleagues; performance; supervisors; teachers; universities 